\title{
AORTIC VALVULAR DISEASE: \\ PATHOPHYSIOLOGY AND ANAESTHETIC MANAGEMENT FOR GENERAL SURGICAL PROCEDURES*
}

\author{
Leonard C. Jenkins, B.A., M.D., C.M., F.R.C.P.(c), † W. A. Dodds, M.D., \\ AND H. B. Graves, B.A., M.D., C.M., F.R.C.P. (C) $) \S$
}

Above all, first, do nothing to harm the patient.

\section{Sir William OsLet ${ }^{1}(1895)$}

PATIENTs with aortic valvular disease, requiring anaesthesia for general surgical procedures, are not uncommon.

During the four-year period from January 1959 until December 1962, 157 patients with aortic valve lesions were anaesthetized at the Vancouver General Hospital for 224 general surgical procedures. The majority of these patients had aortic stenosis alone ( 88 patients) or in combination with aortic insufficiency and/or mitral valvular disease as well (43 patients). Uncommonly, aortic regurgitation was the predominant lesion ( 26 patients; see Table I). These totals do not include pump-oxygenator open-heart patients. Anaesthetic management of this technique will be presented in a separate communication.

TABLE I

General Surgical Patients with Aortic Valvular Disease Requiring ANAESTHESIA

(January 1959-December 1962)

\begin{tabular}{rcccc} 
& \multicolumn{3}{c}{ Lesion } & \\
\cline { 2 - 4 } Year & Aortic stenosis & Aortic regurgitation & Combined & Totals \\
\hline 1959 & 12 & 3 & 16 & 21 \\
1960 & 20 & 6 & 8 & 34 \\
1961 & 27 & 8 & 14 & 49 \\
1962 & 29 & 9 & 15 & 53 \\
Totals & 88 & 26 & 43 & 157 \\
\hline
\end{tabular}

Table II indicates that patients with aortic valvular disease requiring anaesthesia may be involved in a variety of general surgical procedures. These may be grouped into two main categories: (1) general surgery, both elective and emergency, and (2) diagnostic procedures, i.e., left ventricular and femoral artery

-Department of Anaesthesia, Vancouver General Hospital, and the University of British Columbia, Vancouver, British Columbia. Presented at the Western Divisions' Meeting, Canadian Anaesthetists' Society, Regina, Saskatchewan, March 14-16, 1963.

fClinical Assistant Professor, Department of Surgery, Sub-section Anaesthesia, University of British Columbia Medical School.

‡Clinical Assistant Professor, Department of Surgery, Sub-section Anaesthesia, University of British Columbia Medical School.

§Clinical Associate Professor, Department of Surgery, Sub-section Anaesthesia, University of British Columbia Medical School, and Director of Anaesthesiology, Vancouver General Hospital. 
TABLE II

General Surgical Procedures with Anaesthesia on Patients WITH AORTIC VALVULAR DISEASE

(January 1959-December 1962)

\begin{tabular}{crrrrr}
\hline & \multicolumn{4}{c}{ Year } \\
\cline { 3 - 5 } Procedures & 1959 & 1960 & 1961 & 1962 & Totals \\
\hline 1. General surgery & 11 & 13 & 22 & 24 & 70 \\
$\quad$ Elective & 1 & 4 & 5 & 6 & 16 \\
$\quad$ Emergency & & & & & \\
2. Diagnostic & 14 & 26 & 29 & 32 & 101 \\
L.V. puncture & 2 & 9 & 11 & 12 & 34 \\
L.A. puncture & 0 & 0 & 1 & 2 & 3 \\
Cardiac catheterization & 28 & 52 & 68 & 76 & 224 \\
Totals & & & & & \\
\hline
\end{tabular}

puncture, left atrial puncture, and right-heart catheterization. It is anticipated that such diagnostic procedures requiring anaesthesia will become more common in the future, and may be carried out in centres other than where open-heart surgery is performed, as advances in definitive corrective aortic valve surgery are made. That this trend has already begun is also apparent from Table II, which shows the increase in the number of left ventricular and femoral artery punctures from 14 patients in 1959 to 26 in 1960, 29 in 1961, and 32 in 1962.

Patients with aortic valvular disease present perhaps the gravest anaesthetic risks of all cardiac patients. They may appear in any general practice of anaesthesia, and are becoming a more common anaesthetic problem. Therefore, it seems timely and useful, and it is the purpose of this presentation, to carry out a review of their problems in relationship to anaesthesıa, so that we as anaesthetists may provide optimum conditions for the surgical procedures and for the safety of these tenuously balanced patients. Sir William Osler's dictum, "Above all, first, do nothing to harm the patient," 1 was perhaps, from the anaesthetist's point of view, never so true as for this group of patients.

\section{PATHOPHYSIOLOGY}

An understanding of the pathophysiology of aortic valvular disease provides an excellent guide to the formation of fundamental principles in anaesthetic management.

\section{A. Aetiology}

In most instances the cause of aortic stenosis is previous rheumatic fever, atherosclerosis, or congenital bicuspid valves. Not uncommonly, it may be due to congenital subaortic stenosis. Questionably, calcific aortic stenosis from hypercholesteraemic xanthomatosis has been implicated as a separate aetiological factor, but this lesion may prove to be a variant of a chronic rheumatic lesion, or atherosclerosis.

Aortic insufficiency may be caused by congenital prolapsed bicuspid valves, 
alone or in association with coarctation of the aorta, ventricular septal defect, or rheumatic fever. Rheumatic fever, syphilis, and atherosclerosis are more common causes. It may appear, classically in the male, as a complication of rheumatoid arthritis or rheumatoid spondylitis. Rarely, bacterial endocarditis will cause aortic insufficiency, as will a dissecting aneurysm, stretching of the aortic ring from severe hypertension, fenestration of aortic cusps and medial necrosis, with widening of the root of the aorta, sometimes associated with arachnodactyly, as in Marfan's disease.

\section{B. Haemodynamic Alterations}

The haemodynamic alterations in aortic stenosis are summarized in Figure 1(B). They are correlated with the E.C.G. and phonocardiogram. Catheterization of the left heart by percutaneous left ventricular puncture in aortic stenosis will reveal a gradient between the systolic pressure in the left ventricle and in the aorta, brachial, or femoral artery. In this illustration (Fig. $1(B)$ ), a gradient of approximately $100 \mathrm{~mm}$. $\mathrm{Hg}$ exists. This contrasts markedly with the normal left ventricular-aortic pressure curves in Figure 1(A). If the cardiac output is measured, a calculation of the aortic valve area may be made from these data. ${ }^{2}$ Reduction from the normal area of $3.0 \mathrm{sq} . \mathrm{cm}$. to an area of $0.5 \mathrm{sq} . \mathrm{cm}$. indicates severe aortic stenosis. ${ }^{3}$ Note that in aortic stenosis (Fig. 1(B)) there is (i) a slower-rising aortic pressure pulse with (ii) a lower anacrotic notch, (iii) $a^{\prime}$

\section{Hemodynamics of the Aortic Valve}

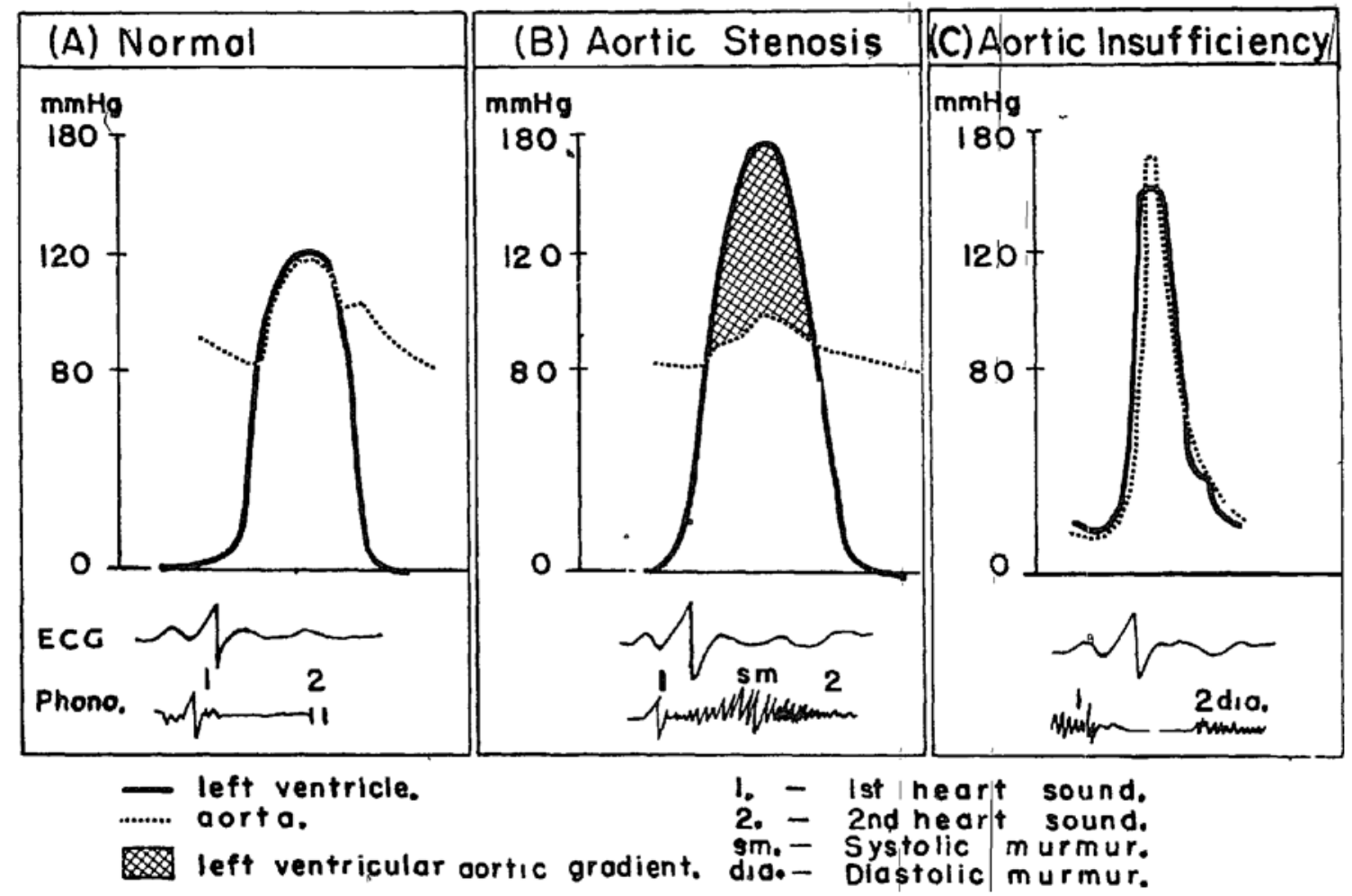

Figure 1. 
reduced maximum pressure, and (iv) a more prolonged ejection phase ${ }^{4}$ than in a normal (Fig. I(A)) pressure curve.

Quantitation of the degree of aortic insufficiency may also be made at the time of left-heart catheterization. The regurgitant fraction of an indicator substance injected into the aorta is measured in the left ventricle. Radiographic visualization of the regurgitating radio-opaque substance may be performed.5 Figure $1(\mathrm{C})$ illustrates the haemodynamic curves found in the markedly increased pulse pressure in aortic insufficiency, in this instance close to $120 \mathrm{~mm}$. Hg. It also illustrates the increased end-diastolic left ventricle pressure curve.

\section{Clinical Manifestations}

These marked haemodynamic alterations in aortic valvular disease manifest themselves in characteristic clinical presentations.

In patients with aortic stenosis, the classical presenting history is syncope on exertion and angina pectoris. Even without anaesthesia sudden death may occur. On examination these patients have a loud, rough systolic murmur, as visualized in Figure 1(B) in the phonocardiogram. It is loudest in the second right intercostal space. It is well transmitted into the neck. There is an associated palpable thrill. The second aortic sound is decreased or absent (Fig. 1(B)). A slowly rising pulse of low volume, or plateau pulse, is felt. That is, a narrow pulse pressure is present, as depicted in Figure 1(B). The E.C.G. shows left ventricular preponderance, with T-wave inversion. Frequently, the coved T-waves of myocardial hypoxia are encountered. A left bundle branch block may be present. There may be atrial fibrillation. In addition, certain arrhythmias are likely to be encountered during anaesthesia for these patients. These, will be mentioned and the method of their management indicated, during the discussion on anaesthetic management. Fluoroscopy may demonstrate calcification in the region of the aortic cusps. There are often associated occlusive calcific coronary artery ostia.

When aortic insufficiency predominates, the presenting history may include angina, paroxysmal nocturnal dyspnoea, and congestive heart failure. Again, with no anaesthesia at all, sudden death is not uncommon. These hearts fibrillate easily and are refractory to electrical defibrillation. On examination there is a high-pitched, blowing diastolic murmur, which may be visualized in the phonocardiogram as in Figure 1(C). It is loudest in the aortic area, or above the left sternal border. If the murmur is faint, hearing it may be facilitated by listening with the breath held at the end of expiration, with the patient leaning forward. An Austin-Flint murmur mimicking mitral stenosis has been described. The peripheral signs in aortic insufficiency are also important. There is a wide pulse pressure, as graphically represented in the aortic pressure curve in Figure $1(C)$. It manifests classically as the "water-hammer" (Corrigan) pulse or the collapsing pulse. A pistol-shot sound, the double Duroziez murmur, and the Quincke capillary pulse are the result of a leak from the arterial system with an associated peripheral vasodilatation. Chest film shows an enlarged left ventricle. The E.C.G. shows left ventricular hypertrophy and "strain" (Fig. 1(C)). Fluoroscopy demonstrates a localized apical thrust due to the enlarged left ventricle. 


\section{Anaesthetic Management}

\section{A. Assessment for Anaesthesia}

Succinctly then, because these patients have an obstructive or regurgitant lesion at the aortic valve site, and an associated striking secondary hypertrophy of the left ventricle, they develop an increasingly fixed cardiac output. Coronary. blood flow becomes progressively inadequate to meet the increased metabolic demands of their already overworked left ventricle. Thus, it is readily imaginable that they present as fragile, tenuous anaesthetic risks, with minimal cardiovascular reserve. During anaesthesia, any patient is confronted with the ever-present danger of the development of hypoxia, hypercarbia, and hypotension. For the patient with aortic valve lesions, these complications are even more hazardous. In these patients, even slight degrees of hypotension reduce the cardiac output sufficiently to upset their balance and decrease effective coronary blood flow. It is perhaps pertinent at this time to remember that the mortality rate in surgical patients with coronary artery disease is twelve times as high as in surgical cases without heart disease. ${ }^{6}$

Patients with aortic valvular disease are more commonly male. They are often big, heavily muscled individuals. The usual dose-weight relationship for drugs used in pre-anaesthetic medication can be hazardously misleading. Agents used for induction and maintenance of anaesthesia must be administered with caution. These patients, although physically robust in superficial appearance, are sensitive to the haemodynamic effects of central nervous system depressants. However, successful intracardiac operations for valvular disease upon desperately sick patients have demonstrated that these drugs may. be used successffully for the cardiac patient who requires anaesthesia, providing proper attention and consideration and care is taken by the-anaesthetist.

In assessing the effects of anaesthetic agents on the heart] an evaluation of direct and indirect actions of the specific anaesthetic drug must be realized (see Table III). The direct action involves the effect on myocardial contractility and rate. The indirect effect is by action of the drugs on central venous pressure, arterial systemic and pulmonary pressures, autonomic nervous system activity, hormonal liberation, and the resulting over-all effect on cardiac output. Table III summarizes the haemodynamic effects of the commonly used anaesthetic drugs on premedicated patients with normal intact cardiac function.

\section{B. Pre-anaesthetic Medication}

Pre-anaesthetic medication with morphine sulphate, particularly when cyclopropane anaesthesia is to be used subsequently, does have an effect on cardiac function. ${ }^{7}$ Heart rate and cardiac output are both decreased during cyclopropane anaesthesia when morphine sulphate is used as premedication (Table III). When morphine is withheld, or when a light dose of meperidine $\mathrm{HCl}$ is used instead, heart rate and cardiac output tend to remain unchanged during subsequent cyclopropane anaesthesia. This action of meperidine $\mathrm{HCl}$ is said to be due to its vágolytic properties. ${ }^{8}$ 


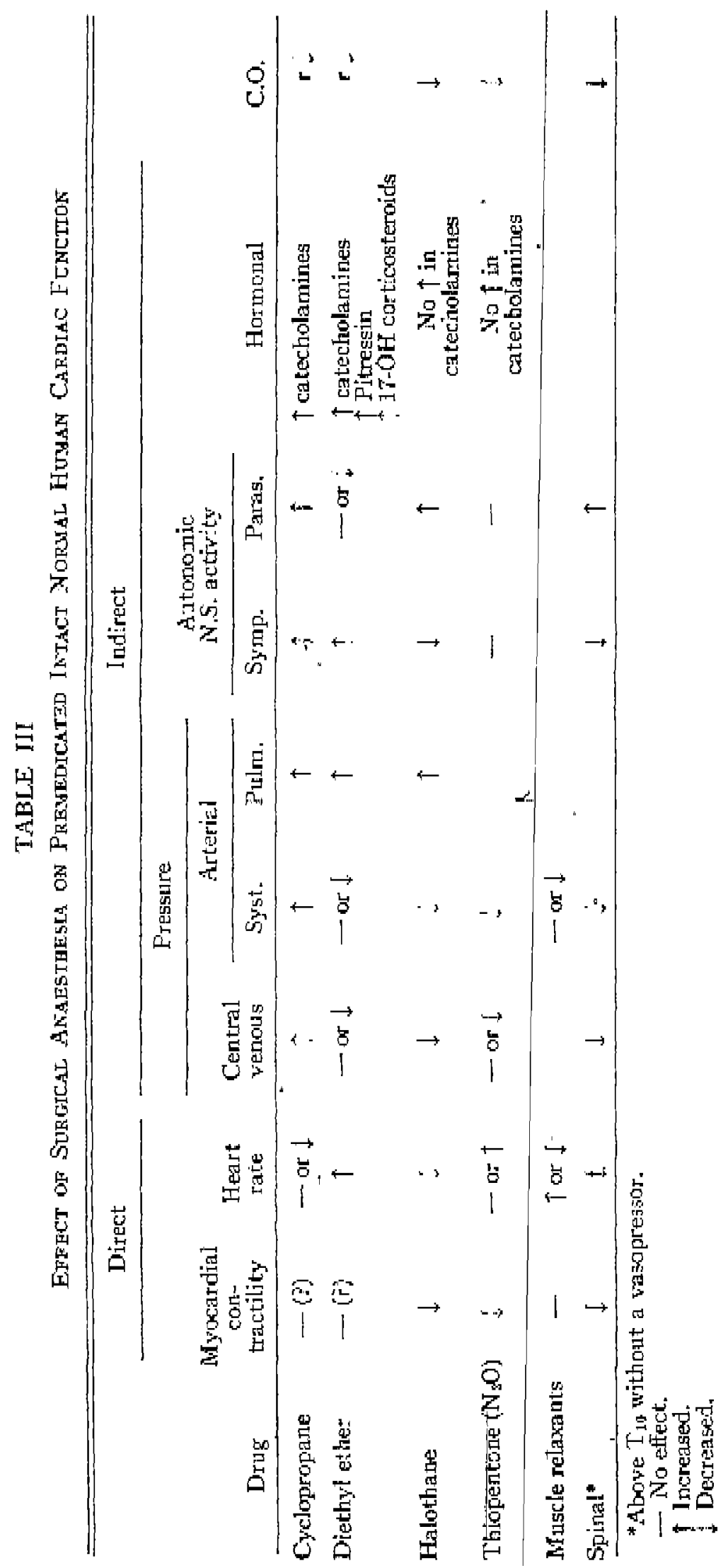




\section{Choice of Agent}

It is interesting to note in Table III that, although myocardial depression has been demonstrated clearly in experimental isolated heart preparations during cyclopropane and diethyl ether anaesthesia, it has not been demonstrated precisely in premedicated intact man. There are so many variables to consider. Probably, there is a depressive effect, but this effect is offset by the increase in circulating plasma levels of catecholamines during anaesthesia with either or both of these agents. ${ }^{9}$ Conversely, halothane will cause a measurable decrease in myocardial contractility but there is no increase in catecholamine concentration in the plasma during anaesthesia with this agent (Table III). There is, in fact, a measurable anti-adrenaline effect. ${ }^{7}$ The-activity of the sympathetic and parasympathetic autonomic nervous systems is increased during cyclopropane anaesthesia, while diethyl ether increases the sympathetic activity only (Table III). There may even be a slight vagal block ${ }^{10}$ with diethyl ether anaesthesia. In contrast to both cyclopropane and ether, and unlike most volatile anaesthetic agents, halothane will decrease the sympathetic and increase the parasympathetic autonomic nervous system activity ${ }^{7}$ (Table III). No demonstrable effect on autonomic nervous system activity is apparent following thiopentone anaesthesia.

It is of major importance to note this widespread haemodynamic influence of the autonomic nervous system activity on the cardiovascular function of man during inhalational anaesthesia. The increase in concentration of catecholamines in plasma associated with the increase in the levels of pitressin and $17-\mathrm{OH}$ corticosteroids, noted especially during diethyl ether anaesthesia, ${ }^{7}$ suggests that the hypothalamic area may assume importance in these considerations.

The increase in the central venous and pulmonary artery pressures during cyclopropane anaesthesia is of special interest (Table III). This increased venous pressure renders the right heart and great intrathoracic veins relatively incompressible, and tends to diminish the circulatory effects produced by inflating the lungs under positive pressure. ${ }^{7}$ Probably for this reason, in our experience, positive-pressure lung inflation in patients with aortic valvular disease and anaesthetized with cyclopropane produced less arterial hypotension than occurred when thiopentone or other general anaesthetics (halothane, diethyl ether) were used. When halothane or ether is used with controlled positive pressure respiration it is suggested that an adequate expiratory pause be allowed, thus improving venous return.

The aim of any anaesthetic technique for these patients is to provide as little impairment or derangement of their haemodynamic reserve as possible, and to maintain a stable cardiac output coronary perfusion ratio. Hypotension must be avoided and prevented.

It is important in these patients that care be exercised during induction and maintenance of anaesthesia, particularly when the sequence of induction with thiopentone-succinylcholine for intubation and cyclopropane or halothane for maintenance is followed. There should not be an indiscriminate routine for these patients. As may be seen from Table III, potent parasympathetie discharges may result, producing a significant bradycardia and followed in order by arterial hypo- 
tension, decreased venous return, decreased cardiác' output, decreased coronary perfusion, and finally asystole or ventricular fibrillation.

The ventricles of patients with aortic insufficiency are markedly atonic and hypertrophic. They respond poorly to treatment. Any critical decrease in coronary artery flow may result in anoxia to either ventricle. The first signs of danger are the occurrence of ventricular extrasystoles, followed by ventricular tachycardia and, within 15 to 30 seconds, by ventricular fibrillation. Once ventricular fibrillation occurs in these patients, prognosis is poor.

Certain arrhythmias are not infrequently encountered during maintenance anaesthesia for these patients, particularly during anaesthesia for left ventricular puncture. E.C.G. monitoring should be used during this procedure. Premature ventricular extrasystoles and ventricular tachycardia are disturbing abnormal rhythms. The anaesthetist should be prepared to combat arrhythmias by maintaining good coronary artery filling and oxygenation. Isuprel $(1: 250,000$ in 5\% G/W I.V. drip), which stimulates the supraventricular pacemaker, may be used to maintain cardiac output if severe heart block occurs. An irritable heart may require dilantin sodium (250-500 mg. I.V.). Calcium chloride (10\%) (0.5-1.0 gm.) may be helpful for the atonic heart.

\section{Choice of Technique}

Meticulous attention should be given to maintenance of normal oxygen saturation, $\mathrm{pO}_{2}, \mathrm{pCO}_{2}$, and $\mathrm{pH}$. Hypoxia and hypercarbia must be avoided. To accomplish this, and in view of the available pharmacological information reviewed in Table III, it would seem that field block, spinal, or peridural anaesthesia would be preferable for lower limb, perineal, and lower abdominal surgery. One must remember that even the local anaesthetic drugs themselves can depress the conducting mechanism of the heart if they are absorbed in sufficient concentration. ${ }^{8}$ Where regional anaesthesia is not applicable, well-conducted, light, general anaesthesia under cyclopropane would seem a good choice. This is a particularly good agent when controlled or assisted respiration with muscle relaxants and positive-pressure ventilation is employed, as the increased central venous and pulmonary artery pressures seen with this agent allow for adequate venous return and subsequent stability of cardiac output. Equally important, adequate surgical anaesthesia with a high concentration of oxygen and low anaesthetic concentration is easily obtainable. Where a non-explosive technique is required, i.e., left ventricular puncture with radiographic control, fluothane with oxygen or 50 per cent nitrous oxide may be used. If at all possible, concentrations of 2 per cent fluothane should be avoided as cardiac output falls appreciably with this concentration. ${ }^{9}$ If controlled positive-pressure respiration is necessary with this agent, an adequate expiratory pause should be instituted to allow for effective venous return. As an alternative non-explosive technique we have used nitrous oxide (50-66\%) with 0.4 per cent meperidine drip and $d$-tubocurare for muscle relaxation when necessary. Transtracheal injection of $2-5$ c.c. 4 per cent xylocaine has been a helpful adjunct to general anaesthesia for left attrial puncture, via bronchoscopy, when combined aortic and mitral valve disease is being investigated.

Regardless of the agent or technique finally selected, the anaesthetist must 
provide constant and accurate care. Additional monitoring aids, such as the Wright spirometer, E.C.G., and Astrup microchemical analyser for $\mathrm{pH}, \mathrm{pCO}_{2}$, $\mathrm{HCO}_{3}$, are useful and desirable in the more major surgical procedures on these patients, but these monitoring aids should not substitute for first-class personal anaesthetic management. Determination of blood volume before, during and after surgery is desirable. An electrical defibrillator (external-internal) should be readily available. The D.C. defibrillator has been particularly useful in the refractory fibrillation associated with aortic disease.

\section{E. Postanaesthetic Care}

The general features and management of problems common to any surgical patient during the postanaesthetic period have been reviewed recently. ${ }^{11}$ They certainly apply even more to this group of patients. The careful attention established during anaesthesia must be maintained, especially with regard to the maintenance of the patient's normal arterial and venous pressures, $\mathrm{pCO}_{2}, \mathrm{pO}_{2}$, and $\mathrm{pH}$.

Pericardial effusion may develop following percutaneous left ventricular puncture. Signs and symptoms of cardiac tamponade should be watched for, following this diagnostic procedure.

\section{SumMary}

Over the past four years 157 patients with aortic valvular disease have been anaesthetized at the Vancouver General Hospital for a variety of 224 surgical procedures, other than for definitive pump-oxygenator open-heart surgery. Patients presenting with this disease are therefore not uncommon and the number has shown a steady progressive increase each year. Two categories of surgery are usually involved: (1) general, elective or emergency, (2) diagnostic, left ventricular and femoral artery puncture, left atrial puncture, and cardiac catheterization. It is anticipated that there will be an increase in the number of diagnostic procedures requiring anaesthesia as more successful definitive |corrective surgery is made available.

The pathophysiology of these patients is such that they| develop a striking secondary obstructive or regurgitant hypertrophy of the left ventricle, which leads to an increasingly fixed cardiac output: They develop progressively an inadequate coronary blood flow to meet the increased demands of an already overworked left ventricle. Thus, they are fragile, grave anaesthetic risks in a tenuous haemodynamic balance. Their cardiovascular compensatory mechanisms are limited.

Anaesthetic management requires meticulous, constant care in the avoidance of hypoxia, hypotension, and hypercarbia. Normal oxygen saturation, $\mathrm{pO}_{2}, \mathrm{pCO}_{2}$, and $\mathrm{pH}$ must be maintained. This approach to management is important and is emphasized, rather than dogmatically recommending a mandatory agent or technique. Nevertheless, in the light of available information on the direct and indirect effects of anaesthesia on normal intact human cardiac function after premedication, various approaches suggest themselves as being more advantageous than others, depending upon requirements that are to be fulfilled. Such 
modifying requirements are site and posturing of operation, "explosive" or "nonexplosive" surgical procedure, and the need for controlled positive-pressure respiration associated with muscle relaxants.

Although there is no substitute for accurate personal clinical conduct of the anaesthetic, useful additional monitors, such as blood volume determinations, Wright spirometer, and Astrup microchemical analyser for $\mathrm{pH}, \mathrm{pCO}_{2}$, and $\mathrm{HCO}_{3}$, can provide helpful guiding information during the more major general surgical procedures on these patients.

We should attempt to follow Sir William Osler's dictum in 1895: "Above all, first, do nothing to harm the patient."

\section{RÉSUMÉ}

Au cours des quatre dernières années, à l'Hôpital Général de Vancouver, nous avons anesthésié 157 malades, porteurs de maladie valvulaire jaortique; ils ont subi une variété de 224 opérations ne comprenant aucun cas de chirurgie à cœur ouvert avec circulation extracorporelle. Cest affirmer que ces malades ne sont plus des cas isolés et, d'année en année, leur nombre semble augmenter. Il y a deux sortes de chirurgie à faire: (1) une chirurgie générale, élective ou urgente; (2) une chirurgie diagnostique, ponction de l'artère fémorale ou du ventricule gauche, ponction de l'oreillette gauche et cathétérisme cardiaque. On anticipe qu'un nombre croissant de techniques diagnostiques |exigeant une anesthésie vont apparaître à meśure que la chirurgie met à point avec succès des opérations qui donnent des résultats définitifs.

La physiopathologie de ces malades nous permet de constater des obstructions secondaires étonnantes ou une hypertrophie ventriculaire gauche de régurgitation qui aboutissent à un débit cardiaque de plus en plus constant. Aussi voit-on apparaître un débit coronarien de plus en plus réduit pour un ventricule gauche déjà surmené et dont les exigences augmentent. En conséquence, ce sont des malades délicats, fragiles, des risques anesthésiques graves, des porteurs d'un équilibre hémodynamique instable. Leurs $\mid$ mécanismes compensateurs cardiovasculaires sont limités.

La conduite de l'anesthésie, chez ces malades, demande une surveillance méticuleuse constante pour éviter toute hypoxie, hypotension et rétention de $\mathrm{CO}_{2}$. Il faut à tout prix maintenir la saturation en oxygène, la $\mathrm{pO}_{2}$, la $\mathrm{pCO}_{2}$ et le $\mathrm{pH}$. Plutôt que de recommander, de façon dogmatique, un agent et une technique obligatoires, nous insistons sur l'importance de cette conception dans la conduite de l'anesthésie. Toutefois, à la lumière des renseignements obtenus sur les effets directs et indirects de l'anesthésie sur la fonction cardiaque humaine normale et intacte après une prémédication, il s'impose de nouvelles voies d'abord qui semblent plus avantageuses que d'autres selon les exigences à rencontrer. Ces exigences qui influencent notre conduite sont le site de l'opération et la position du malade durant l'opération, la technique chirurgicale susceptible ou non de provoquer des explosions, et la nécessité d’utiliser la respiration contrôlée avec pression positive associée aux myorésolutifs. 
Sachant qu'il n'y a rien pour remplacer, dans la conduite d'une anesthésie, le sens clinique personnel et bien à point, il peut toutefois être utile de se' servir de moniteurs additionnels, comme la détermination du volume sanguin, l'usage du spiromètre de Wright et celui de l'analyseur microchimique de Astrup pour donner le $\mathrm{pH}$, la $\mathrm{pCO}_{2}$ et la $\mathrm{HCO}_{3}$; chez ces malades, au cours des opérations générales majeures, ces instruments peuvent fournir des renseignements précieux pour nous orienter.

Il nous faut essayer de suivre le conseil donné par Sir William Osler en 1895: "D’abord, avant tout, il ne faut pas nuire au malade."

\section{REFERENCES}

1. OsLer, Sir WIILIAM. The Principles and Practice of Medicine; Designed for the use of Practitioner and Students of Medicine. 2nd ed. New York: Appleton (1895).

2. Gorurn, R. \& Gorunv, S. G. Hydraulic Formula for the Calculation of the Area of the Stenotic Mitral Valve, Other Cardiac Valves and Central Circulating Shunts. Am. Heart J. 41: 1 (1951).

3. Gorlin, R.; McMmlan, K. R.; Medd, W. E.; Mathews, M. D.; \& Daler, R. Dynamics of the Circulation in Aortic Valvular Disease. Am. J. Med. 18: 853 (1955).

4. Woon, P. Aortic Stenosis. Am. J. Cardiol. 1: 553 (1958).

5. Langreld, S. B. Screening the Cardiac Patient. Med. Cl. N. Am. 44: 1589 (1960).

6. Ersten, B. \& Proger, S. Operative Risk in Patients with Coronary Heart Disease. J.A.M.A. 159: 845 (1955).

7. Price, H. L. General Anaesthesia and Circulatory Homeostasis. Physiol. Rev. 40: 187 (1960).

8. DoBkIN, A. B. The Effects of Anaesthetic Agents on the Cardiovascular System: A Review. Canad. Anaesth. Soc. J. 7: 317 (1960).

9. ETsten, B. \& LI, T. H. Effects of Anaesthesia upon the Heart. Am. J. Cardiol. 6: 706 (1960).

10. Prrce, H. L. General Anaesthesia and the Circulation. Clin. Pharmacol. and Therap. 2: 163 (1961).

11. Jenkms, L. C.; Donds, W. A.; \& Graves, H. B. The Role of the Anaesthetist in the Postanzesthetic Period. Canad. Anaesth. Soc. J. 9: 331 (1962). 